\title{
AVALIAÇÃO PRELIMINAR DAS AÇÕES DE PUERICULTURA EM EQUIPE DE SAÚDE DA FAMÍLIA, ENTRE BENEFICIÁRIOS E NÃO- BENEFICIÁRIOS DO PROGRAMA BOLSA FAMÍLIA
}

\author{
César Luiz Silva Junior \\ Cirurgiāo Dentista, Escola Nacional de Saúde Pública, \\ cesarluiz54@gmail.com \\ Ana Elisa Medeiros Barbar
}

Psicóloga, Escola Nacional de Saúde Pública, aembarbar@gmail.com

Camila da Silva de Oliveira Assistente Social, Escola Nacional de Saúde Pública, camilaa@id.uff.br

Marina Helena Marques do Rosário Enfermeira, Escola Nacional de Saúde Pública, marinahelena.mr@gmail.com Tamara Maria Pinheiro Nutricionista, Escola Nacional de Saúde Pública, tamara.pinheiro9@gmail.com José Wellington Gomes Araújo Doutor, Escola Nacional de Saúde Pública da Fundação Oswaldo Cruz, well@ensp.fiocruz.br

Guido Antonio Espírito Santo Palmeira Mestre, Escola Nacional de Saúde Pública da Fundação Oswaldo Cruz, guidopal@ensp.fiocruz.br 


\section{Arlinda B. Moreno}

Doutora, Escola Nacional de Saúde Pública da Fundação Oswaldo Cruz, morenoar@fiocruz.br

\section{RESUMO}

O acompanhamento da saúde de crianças permanece como prioridade pelo Ministério da Saúde (MS), em consonância com as metas estabelecidas pela Organização Mundial da Saúde (OMS). No âmbito da atenção básica em saúde (ABS), a partir de 2002, o MS lançou cadernos de atenção básica voltados à saúde da criança, com diversas ações multiprofissionais para a melhoria no acompanhamento em saúde e no desenvolvimento dessa população. Como componente da ABS, a Estratégia Saúde da Família (ESF), ao realizar a puericultura, deverá considerar diferentes determinantes de saúde e de doença em suas ações - desde o ambiente físico da comunidade até as relaçóes sociais desenvolvidas no território, para além do tratamento de doenças. A partir dessa compreensão de saúde em suas diversas determinaçóes, as questóes referentes às desigualdades sociais e à pobreza têm impactos significativos na situação de saúde da população. Na última década, o Governo Federal desenvolveu diversos programas buscando mitigar a situação de pobreza no Brasil, tendo como destaque o Programa Bolsa Família (PBF), que tem por objetivo promover o acesso à rede de serviços públicos, especialmente de saúde, de educação e de assistência social. Uma das questóes que se levanta, a partir da relação intersetorial entre assistência e saúde, é se efetivamente há uma melhoria nas condições de saúde e minimização da pobreza dessa populaçáo - considerando-se as condicionalidades do programa - e como se dá esse acompanhamento nas Unidades Básicas de Saúde (UBS). Em face desses questionamentos, a equipe multiprofissional de residentes em Saúde da Família (ENSP/FIOCRUZ), tendo por ensejo a realização de trabalho epidemiológico dialogado com o campo de prática, buscou avaliar açóes de puericultura realizadas por uma equipe de Estratégia Saúde da Família (ESF), no município do Rio de Janeiro, comparando suas características a partir de dois grupos distintos: beneficiários e não-beneficiários do PBF. Foram analisados, por 
meio de estatística descritiva, os prontuários de todas as crianças menores de sete anos cadastradas no território adscrito pela eSF, em 26 de novembro de 2015. A coleta de dados se deu a partir do sistema eletrônico VitaCare, em um universo de 412 prontuários, cujas variáveis puderam ser rastreadas ao longo dos dois meses seguintes. Para a coleta de dados, visando à conformação de uma nova base de dados para análise, utilizou-se o programa EpiData 3.1 e, no programa Epi Info $^{\text {тм }}$ 7.1.4.0, efetivou-se a análise dos dados. Dentre os 412 prontuários analisados, observou-se que 64 (15,53\%) crianças são beneficiárias do PBF. Para este grupo, $81,25 \%$ das crianças tiveram entre uma e nove consultas de puericultura, realizadas desde o cadastro na eSF. Para o grupo de crianças não-beneficiárias, a porcentagem nesta faixa de acompanhamento (1-9 consultas de puericultura) foi de $55,17 \%$, enquanto $42,53 \%$ das crianças neste grupo não possuíram nenhuma consulta desde o cadastramento. No grupo beneficiário do PBF, esta proporção foi de 10,94\%. Em relaçáo à demanda livre, o grupo de beneficiários do PBF apresentou maior frequência $(62,49 \%)$ quando comparado ao de não-beneficiários $(31,04 \%)$. Os dados preliminares aqui apresentados possibilitaram o surgimento de novas questóes acerca do acompanhamento em saúde de crianças pela ESF, tais como a relação entre o alto número de demandas livres nas crianças beneficiárias do Bolsa Família e uma maior proporção de consultas de puericultura neste grupo. Foi possível levantar hipóteses que justificariam esses resultados, como, por exemplo, por um lado, o vínculo com equipe, gerado a partir do acompanhamento de condicionalidades, e, por outro lado, a situação de vulnerabilidade na qual se encontram as famílias beneficiárias, o que poderia demandar da ESF mais cuidados em saúde. Este estudo faz parte de um projeto maior de investigação do acompanhamento de puericultura na ESF referida, a ser finalizado até março de 2017. Foram encontradas limitações no desenvolvimento da pesquisa, a partir do uso (para coleta de dados) de sistema eletrônico de registro dos prontuários, pois este apresentou problemas de preenchimento e de atualização dos dados. Apesar dos achados serem iniciais e, portanto, haver necessidade de maior aprofundamento, observou-se que crianças beneficiárias do PBF possuem maior número de consultas programadas, sugerindo que o benefício possibilitaria uma melhora quantitativa do acompanhamento de puericultura desse grupo. 
Palavras-chave: Avaliação em Saúde; Atenção Primária à Saúde; Saúde da Criança; Vulnerabilidade em Saúde; Equidade no Acesso.

\section{REFERÊNCIAS}

BRASIL. Secretaria de Atenção à Saúde. Saúde da criança: crescimento e desenvolvimento. Brasília: Ministério da Saúde, 2012. 